\title{
RP-HPLC METHOD DEVELOPMENT AND VALIDATION FOR SIMULTANIOUS ESTIMATION AND FORCED DEGRADATION STUDIES OF LAMIVUDINE AND RALTEGRAVIR IN SOLID DOSAGE FORM
}

\author{
JULURI KRISHNA DUTTA TEJASWI ${ }^{*}$, R. GOVINDA RAJAN² \\ 1Department of Pharmaceutical Analysis, College of Pharmaceutical Sciences, Acharya, Nagarjuna University, Guntur (AP), India, \\ ${ }^{2}$ Department of Pharmaceutical Chemistry, Hindu College of Pharmacy, Amaravathi Road, Guntur (AP), India \\ Email: y2kteja@gmail.com
}

Received: 18 Jun 2018, Revised and Accepted: 04 Oct 2018

ABSTRACT

Objective: A stability indicating reverse phase high-performance liquid chromatography (RP-HPLC) method was developed and validated for the estimation of the combined tablet formulation of lamivudine (LAM) and raltegravir (RAL) in dosage forms and its API.

Methods: Chromatographic separation was achieved on inertsil ODS C18 $5 \mu \mathrm{m}$ (4.6 X $150 \mathrm{~mm}$ ) using a mobile phase (MP) consisting of a mixture of mixed orthophosphoric acid (OPA): acetonitrile (ACN) in the ratio 50:50 v/v which was determined at $242 \mathrm{~nm}$ respectively.

Results: The assay of LAM and RAL was performed with tablets, and the \% assay was found to be 100.12 and 99.89 which shows that the method is useful for routine analysis. The linearity of LAM and RAL was found to be linear with a correlation coefficient of 0.998 and 0.999 , which shows that the method is capable of producing good sensitivity. The retention time of LAM and RAL was $1.99 \mathrm{~min}$ and 4.34 min respectively; linearity range was found to lie from $15 \mu \mathrm{g} / \mathrm{ml}$ to $75 \mu \mathrm{g} / \mathrm{ml}$ for LAM, $30 \mu \mathrm{g} / \mathrm{ml}$ to $150 \mu \mathrm{g} / \mathrm{ml}$ for RAL with a correlation coefficient of 0.999 respectively. Forced degradation studies were conducted in acidic, basic, thermal, photolytic and peroxide where all the degradation peaks were monitored.

Conclusion: The proposed HPLC method was found to be simple, specific, precise, accurate, rapid and economical for simultaneous estimation of LAM and RAL in bulk and tablet dosage form. Thus the validated economical method was applied for forced degradation study of LAM and RAL tablet.

Keywords: lamivudine, Raltegravir, Acetonitrile, Stability

(C) 2018 The Authors. Published by Innovare Academic Sciences Pvt Ltd. This is an open access article under the CC BY license (http://creativecommons.org/licenses/by/4.0/) DOI: http://dx.doi.org/10.22159/ijap.2018v10i6.28027

\section{INTRODUCTION}

Human immunodeficiency virus (HIV) is a retrovirus that gradually attacks the immune system, which protects the human body against illness. Currently, there is no cure for HIV, but with early diagnosis and effective antiretroviral (ARV) treatment, people with HIV can live a long and normal, healthy life. Therefore, it is important to take the correct treatment regularly.

Lamivudine (LAM) [1-4] belongs to a group of anti-HIV medicines called nucleoside reverse transcriptase inhibitors (NRTI). This nucleoside analogue is incorporated into viral DNA by HIV reverse transcriptase and HBV polymerase, resulting in DNA chain termination. The lack of a $3^{\prime}-\mathrm{OH}$ group in the incorporated nucleoside analogue prevents the formation of the $5^{\prime}$ to $3^{\prime}$ phosphodiester linkage essential for DNA chain elongation, and therefore, the viral DNA growth is terminated. Its chemical formula is 4-amino-1-[(2R,5S)-2-(hydroxymethyl)-1,3-oxathiolan-5-yl]-1,2dihydro pyrimidin-2-one and the molecular formula is $\mathrm{C}_{8} \mathrm{H}_{11} \mathrm{~N}_{3} \mathrm{O}_{3} \mathrm{~S}$.

Raltegravir (RAL) [5-13] is an antiretroviral compound belongs to the class of organic compounds known as pyrimidine carboxylic acids and derivatives. RAL potassium is a pyrrolidinone derivative and an HIV integrase inhibitor that is used in combination with other anti-HIV agents for the treatment of HIV infection. Inhibition (INH) of integrase prevents insertion of HIV DNA into the human DNA genome, thus blocking HIV replication [7, 8]. Its chemical formula is $\mathrm{N}-[2-[4-[(4-$ fluorophenyl)methylcarbamoyl]-5-hydroxy-1-methyl-6-oxopyrimidin2-yl]propan-2-yl]-5-methyl-1,3,4-oxadiazole-2-carboxamide and the molecular formula is $\mathrm{C} 20 \mathrm{H} 20 \mathrm{FKN} 605$.

The previous established methods were found high Rt and increased the total run time for analysis. Literature search reveals that only few analytical methods were reported for simultaneous estimation of LAM and RAL using HPLC $[14,15]$ method according to the international council on harmonization (ICH). There was no stability indicating analytical methods reported for simultaneous estimation of LAM and RAL. The present study was aimed to develop a simultaneous estimation of LAM and RAL along with forced stability studies which were found to be simple, precise, accurate and shorter retention time which makes this method good for routine analysis in research institutions which justify that the developed method is advantageous over the existing method. The structures were given in fig. 1.<smiles>Cn1c(C(C)(C)NC(=O)c2nnc(CNc3ccn([C@H]4CS[C@H](CO)O4)c(=O)n3)o2)nc(C(=O)NCc2ccc(F)cc2)c(O)c1=O</smiles>

(I)

Fig. 1: Structure of LAM (I) and RAL (II) 


\section{MATERIALS AND METHODS}

\section{Chemical and reagents}

Pure samples were obtained as a gift from hetero pharma ltd, hyderabad, india. OPA was obtained from finar chemical ltd. methanol and ACN were obtained from rankem india ltd.

\section{Preparation of buffer and mobile phase}

Pipette out $1 \mathrm{ml}$ of $0.1 \%$ OPA in $900 \mathrm{ml}$ HPLC water in it. Mix well and makeup the volume to $1000 \mathrm{ml}$ with water used as a buffer. Mix a mixture of above buffer $500 \mathrm{ml}(50 \%)$ and $500 \mathrm{ml}$ ACN HPLC (50\%) in $50: 50 \mathrm{v} / \mathrm{v}$ ratio and degas in ultrasonic water bath for $5 \mathrm{~min}$.

\section{Preparation of standard and sample solutions}

Accurately transfer $15 \mathrm{mg}$ of LAM and $30 \mathrm{mg}$ of RAL working standard into a $10 \mathrm{ml}$ clean dry volumetric flask and sonicate. (Stock solution) Further pipette $1 \mathrm{ml}$ of the above stock solution into a $10 \mathrm{ml}$ volumetric flask and dilute. Further pipette $3 \mathrm{ml}$ of LAM and RAL of the above stock solution into a $10 \mathrm{ml}$ volumetric flask and dilute with diluents.

Accurately transfer $15 \mathrm{mg}$ of LAM and $30 \mathrm{mg}$ RAL equivalent weight of the sample into a $10 \mathrm{ml}$ clean volumetric flask, add about $70 \mathrm{ml}$ of diluents and sonicate. (Sample solution) Further pipette $1 \mathrm{ml}$ of the above solution into a $10 \mathrm{ml}$ volumetric flask and dilute. Further pipette $3 \mathrm{ml}$ of LAM and RAL of solution into a $10 \mathrm{ml}$ volumetric flask and dilute with diluents.

\section{Preparation of mixed standard solution}

Accurately transfer $15 \mathrm{mg}$ of LAM and $30 \mathrm{mg}$ of RAL working standard into a $10 \mathrm{ml}$ clean, dry volumetric flask add diluents and sonicate to dissolve it completely and make volume up to the mark with the same solvent. (Stock solution) Further pipette $1 \mathrm{ml}$ of LAM and RAL of the above stock solution into a $10 \mathrm{ml}$ volumetric flask and dilute up to the mark with diluents. Further pipette $3 \mathrm{ml}$ of LAM and RAL of the above stock solution into a $10 \mathrm{ml}$ volumetric flask and dilute up to the mark with diluents.

\section{Instrumentation}

The proposed method was carried out on inertsil ODS C18 $5 \mu \mathrm{m}(4.6$ $\mathrm{X} 150 \mathrm{~mm}$ ) and the mobile phase consisted of OPA (pH: 3): ACN $(50: 50 \mathrm{v} / \mathrm{v})$ the column temperature was set $25^{\circ} \mathrm{C}$. From the UV spectrum wavelength selected as $242 \mathrm{~nm}$.

\section{Assay procedure}

Inject $20 \mu \mathrm{L}$ of the standard, sample into the chromatography system and measure the assay of LAM and RAL was performed with tablets.

\section{Method validation}

The analytical method was validated with respect to parameters such as linearity, LOQ, LOD, precision, accuracy, selectivity, recovery and ruggedness and was applied for forced degradation studies as per the ICH guidelines. [16-18]

\section{Forced degradation studies}

\section{Acid degradation condition}

Accurately $3.0 \mathrm{ml}$ of stock solution into a $10 \mathrm{ml}$ volumetric flask and $3 \mathrm{ml}$ of $0.1 \mathrm{~N} \mathrm{HCl}$ was added. Then, the volumetric flask was kept at $60^{\circ} \mathrm{C}$ for 6 $\mathrm{h}$ and then neutralized with $0.1 \mathrm{~N} \mathrm{NaOH}$ and makeup to $10 \mathrm{ml}$ with diluent. The solution was filtered through $0.45 \mu$ filter, and then filtrate was injected into system and percentage of degradation was calculated.

\section{Alkali degradation condition}

Accurately $3.0 \mathrm{ml}$ of stock sample into a $10 \mathrm{ml}$ volumetric flask and add $3 \mathrm{ml}$ of $0.1 \mathrm{~N} \mathrm{NaOH}$ was added. Then, the volumetric flask was kept at $60{ }^{\circ} \mathrm{C}$ for $6 \mathrm{~h}$ and then neutralized with $0.1 \mathrm{~N} \mathrm{HCl}$ and makeup to $10 \mathrm{ml}$ with diluent. The solution was filtered through $0.45 \mu$ filter, and then the filtrate was injected into the system and percentage of degradation was calculated.

\section{Thermal-induced degradation condition}

$3 \mathrm{ml}$ of stock sample was taken in petri dish and kept in hot air oven at $110{ }^{\circ} \mathrm{C}$ for $24 \mathrm{~h}$. The samples were then placed in a desiccator till reaching the room temperature. The content in the flasks was dissolved using methanol and diluted up to the mark. Then the sample was taken and diluted with diluents and injected and percentage of degradation was calculated.

\section{Photolytic degradation condition}

Accurately $3.0 \mathrm{ml}$ of stock sample was exposed to sunlight for about $6 \mathrm{~h}$ and then the sample diluted with $5 \mathrm{ml}$ of mobile phase and percentage of degradation.

\section{Oxidative degradation condition}

Accurately $3.0 \mathrm{ml}$ of stock sample into a $10 \mathrm{ml}$ volumetric flask, $1 \mathrm{ml}$ of $3.0 \mathrm{ml}$ of $3 \% \mathrm{H}_{2} \mathrm{O}_{2}$ was added and the volume was made up to the mark with diluent. The volumetric flask was then kept at room temperature for $15 \mathrm{~min}$. The solution was filtered through $0.45 \mu$ filter and then filtrate was injected into the chromatography system and the percentage of degradation was calculated.

\section{RESULTS AND DISCUSSION}

There is no official method for this combination so far. However, few methods have been reported in either of one or two in this combination with some other drugs. For selecting column chiral columns of OD52546 and SCDP 52546 inertsil was chosen to separate LAM and RAL by injecting system suitability solution with the mobile phase at $0.9 \mathrm{ml} / \mathrm{min}$ individually. Various solvents including water, ACN, phosphate buffer, OPA, and methanol were used in different combinations to get good peaks resolutions and lesser runtime. Different flow rates from 0.4 to $1 \mathrm{ml} / \mathrm{min}$ in gradient mode have been studied to achieve a good peak resolution. The column temperature was set at $25^{\circ}, 30^{\circ}$ and $35^{\circ} \mathrm{C}$ for optimizing according to its effect on peak resolutions and retention times of the drug samples. After several initial trials with mixtures of methanol, $\mathrm{ACN}$ and different buffer in various combinations, a trail with a mobile phase mixture of OPA: ACN $(50: 50 \mathrm{v} / \mathrm{v})$ with $25^{\circ} \mathrm{C}$ at $242 \mathrm{~nm}$ the flow rate was $0.9 \mathrm{ml} / \mathrm{min}$ in gradient elution and the injection volume was $20 \mu \mathrm{g} / \mathrm{ml}$ of mixed standard solution and the $\%$ assay was found to be 100.48 and 98.84 which shows that the method was useful for routine analysis under the described experimental conditions, all the peaks were well defined and free from tailing and $\%$ recovery values were shown in table 1 and fig. 2 .

\section{System suitability}

It is defined to measure that can generate the result of acceptable accuracy and precision. The system suitability was carried out after the method development and validation was completed. The retention time of LAM and RAL using optimum conditions were $1.996 \mathrm{~min}$ and $4.336 \mathrm{~min}$ respectively. Resolution between two drugs must be not less than 2 . Theoretical plates must be not less than 2000. Tailing factor must be not more than 2 as shown in table 2 .

Table 1: Assay and \% recovery of LAM and RAL

\begin{tabular}{|c|c|c|c|c|c|c|c|c|}
\hline \multirow[t]{2}{*}{ Drug } & \multirow{2}{*}{$\begin{array}{l}\text { Label } \\
\text { claim (mg) }\end{array}$} & \multirow{2}{*}{$\begin{array}{l}\text { Estimated } \\
\text { claim (mg) }\end{array}$} & \multirow{2}{*}{$\begin{array}{l}\text { Average } \\
\text { area }\end{array}$} & \multirow[t]{2}{*}{ \% Purity } & \multicolumn{4}{|c|}{ \% Recovery (\%) } \\
\hline & & & & & 80 & 100 & 120 & Mean \\
\hline LAM & 150 & 150.72 & 42117.66 & 100.48 & 100.58 & 99.18 & 100.60 & 100.12 \\
\hline RAL & 300 & 296.52 & 215547.33 & 98.84 & 98.94 & 99.67 & 101.07 & 99.89 \\
\hline
\end{tabular}

LAM: lamivudine; RAL: raltegravir 


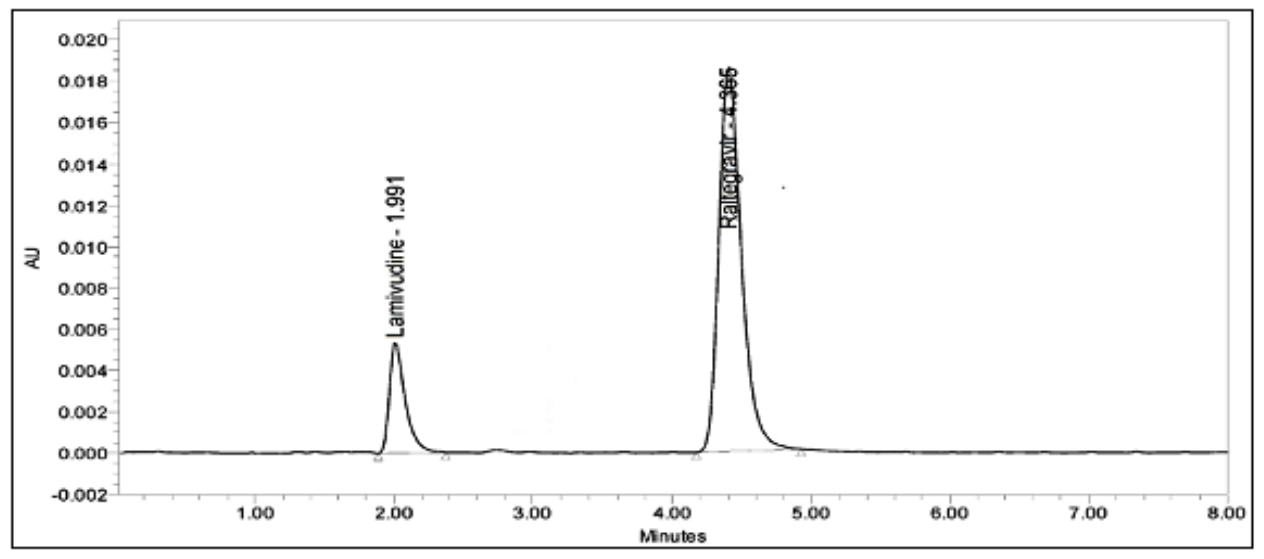

Fig. 2: Assay chromatogram of LAM and RAL

Table 2: System suitability results of LAM and RAL

\begin{tabular}{lll}
\hline Parameter & LAM & RAL \\
\hline Peak area & 42115 & 215502 \\
Theoretical plates (N) & 2559.08 & 3511.35 \\
Retention time (min) & 1.996 & 4.336 \\
Tailing factor (T) & 1.65 & 1.35 \\
\hline
\end{tabular}

LAM: lamivudine; RAL: raltegravir

\section{Specificity}

The specificity of the method was evaluated in a placebo solution and a blank solution were also prepared. In practice, this can be done by spiking the drug substance or product with appropriate levels of excipients and demonstrating that the assay results are unaffected by the presence of these extraneous materials. Optimized chromatogram of LAM and RAL are shown in fig. 3.

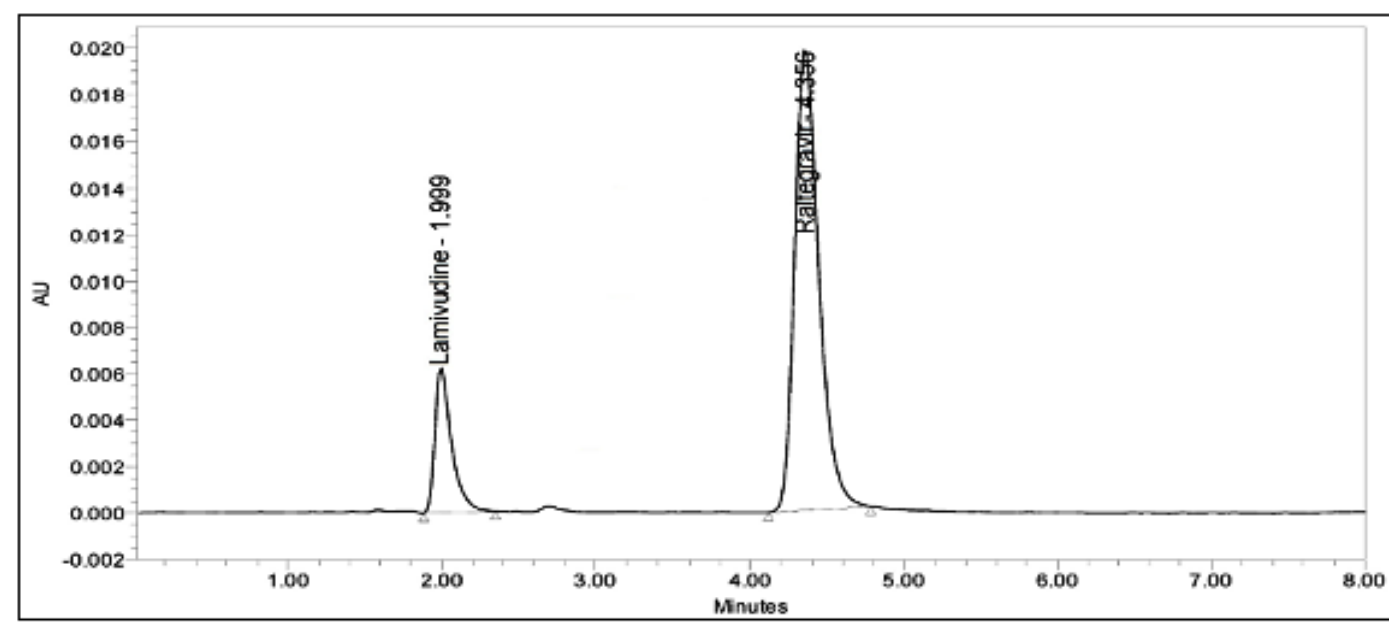

Fig. 3: Specificity chromatogram of LAM and RAL

\section{Linearity}

From the stock solution, inject each level into the chromategraphy system and measure the peak area. Plot a graph of peak area versus concentration and calculate the correlation coefficient. The correlation coefficient obtained was 0.99 which is in the acceptance limit. The linearity range was found to lie from $15 \mu \mathrm{g} / \mathrm{ml}$ to $75 \mu \mathrm{g} / \mathrm{ml}$ of LAM $30 \mu \mathrm{g} / \mathrm{ml}$ to $150 \mu \mathrm{g} / \mathrm{ml}$ of RAL and chromatograms were shown below as shown in fig. 4-5 and table 3.

Table 3: Linearity data of LAM and RAL

\begin{tabular}{llll}
\hline LAM & & RAL & \\
\hline Concentration $(\boldsymbol{\mu g} / \mathbf{m l})$ & Peak area & Concentration $(\boldsymbol{\mu g} / \mathbf{m l})$ & Peak area \\
\hline 15 & 14891 & 30 & 67496 \\
30 & 30568 & 60 & 151923 \\
45 & 43243 & 90 & 223324 \\
60 & 59103 & 120 & 304753 \\
75 & 71989 & 150 & 374626 \\
\hline
\end{tabular}

LAM: lamivudine; RAL: raltegravir 


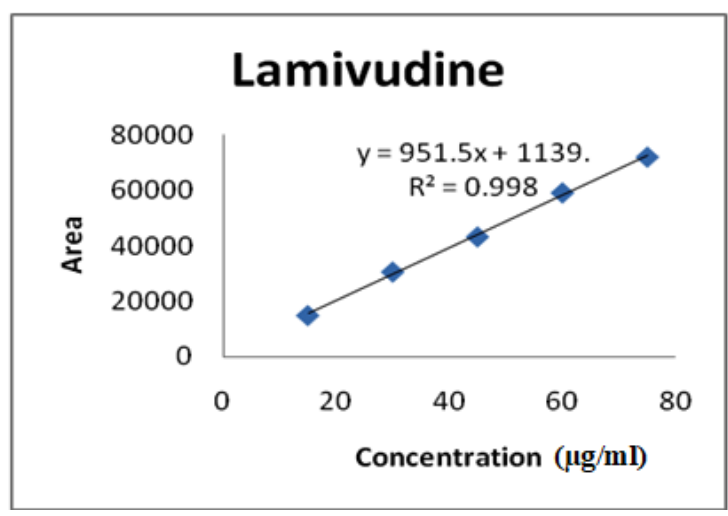

Fig. 4: Linearity graph of LAM

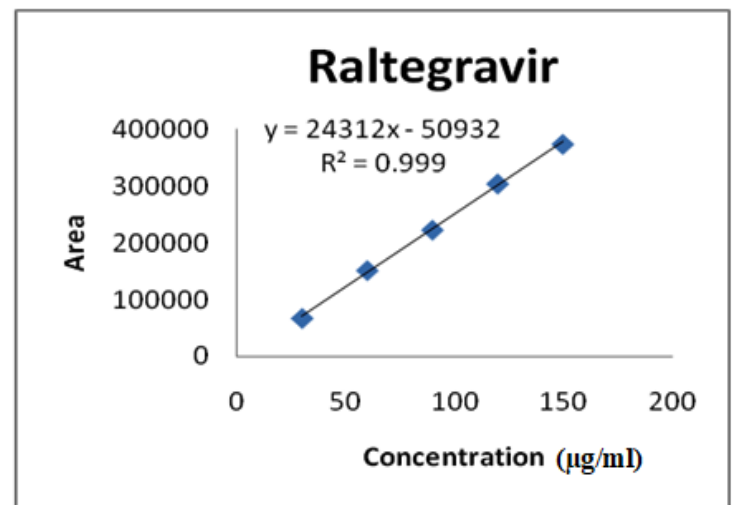

Fig. 5: Linearity graph of RAL

Table 4: Precision data of LAM and RAL

\begin{tabular}{lllll}
\hline Parameter & LAM & & RAL & Peak area \\
\cline { 2 - 5 } & Retention time (min) & Peak area & Retention time (min) & 218798 \\
\hline 1 & 1.991 & 48270 & 4.365 & 216905 \\
2 & 1.984 & 46977 & 4.385 & 216459 \\
3 & 1.989 & 46914 & 4.362 & 221802 \\
4 & 1.991 & 46722 & 4.359 & 218749 \\
5 & 1.995 & 47013 & 4.366 & 21852.6 \\
Average (min) & 1.984 & 47179.2 & 4.355 & 2106.8 \\
SD & 0.002 & 620 & 0.002 & 0.96 \\
\% RSD & 1.32 & 1.31 & 0.92 & \\
\hline
\end{tabular}

$\mathrm{n}=5$; LAM: lamivudine; RAL: raltegravir; SD: standard deviation; RSD: relative standard deviation

\section{Precision}

The standard solution was injected for five times and measured the area in HPLC. \% RSD for sample should be NMT 2. One dilution of all the drugs in six replicates was injected into HPLC system and was analyzed and the results were shown in the table 4.

\section{LOD and LOQ}

LOD and LOQ for LAM and RAL were estimated and as the amounts for the signal to noise ratios were found to be $3: 1$ and 10:1 respectively. LOD values for LAM and RAL were 2.96 and $2.95 \mathrm{~s} / \mathrm{n}$ ratio. LOQ values for LAM and RAL were 9.96 and $9.98 \mathrm{~s} / \mathrm{n}$ ratio. Signal to noise ratio shall be 3 for LOD and 10 for LOQ solution.

\section{Method precision}

The standard solution was injected for five times and measured the area for all five injections. The precision of the method was carried out for both sample solutions as described under experimental work. The corresponding chromatograms and results were below as table 5.

Table 5: Method precision data of LAM and RAL

\begin{tabular}{llll}
\hline Parameter & LAM & & RAL \\
\cline { 2 - 4 } & Retention time (min) & Peak area & Retention time (min) \\
\hline 1 & 2.004 & 48270 & 4.374 \\
2 & 1.999 & 46977 & 4.356 \\
3 & 1.993 & 46914 & 4.358 \\
4 & 1.992 & 46722 & 4.356 \\
5 & 1.990 & 47013 & 4.354 \\
Average (min) & 1.994 & 47179.2 & 4.358 \\
SD & 0.004 & 620 & 0.005 \\
\% RSD & 0.31 & 1.31 & 0.96 \\
\hline
\end{tabular}

$\mathrm{n}=5$; LAM: lamivudine; RAL: raltegravir; SD: standard deviation; RSD: relative standard deviation

Table 6: Ruggedness data for a sample of LAM and RAL

\begin{tabular}{llll}
\hline Parameter & LAM & & RAL \\
\cline { 2 - 4 } & Retention time (min) & Peak area & Retention time (min) \\
\hline 1 & 1.996 & 45921 & 4.382 \\
2 & 2.001 & 47289 & 4.382 \\
3 & 1.992 & 46249 & 4.374 \\
4 & 1.992 & 47758 & 4.75 \\
5 & 1.990 & 47193 & 4.61 \\
Average (min) & 1.992 & 46838.17 & 4.352 \\
SD & 0.004 & 694.5 & 0.005 \\
\% RSD & 0.31 & 1.48 & 219057 \\
\hline
\end{tabular}

$\mathrm{n}=5$; LAM: lamivudine; RAL: raltegravir; SD: standard deviation; RSD: relative standard deviation 


\section{Ruggedness}

To evaluate the ruggedness of the method, precision was performed on a different day within the laboratory. \%RSD of five different sample solutions should not more than 2 . There was no significant change in assay content and system suitability parameters at different conditions of ruggedness like day to day and system to system variation. The standard solution was injected for five times and measured the area for all five injections as shown in tables 6 .

\section{Accuracy}

For accuracy determination, three different concentrations were prepared separately, i.e. $50 \%, 100 \%$ and $150 \%$ for the analyst and chromatograms were recorded for the same. Calculate the amount found and amount added for LAM and RAL and calculate the individual recovery and mean recovery values. The percentage recovery was found to be within the limit (97-103\%).

The results obtained for recovery at 50\%, 100\%, 150\% are within the limits. Hence method is accurate. The results were given in tables 7.

Table 7: Recovery data of LAM and RAL

\begin{tabular}{|c|c|c|c|c|c|c|}
\hline Drug & Sample & Amount added $(\mu \mathrm{g} / \mathrm{ml})$ & Amount found $(\mu \mathrm{g} / \mathrm{ml})$ & Area & \% Mean & \% Average \\
\hline \multirow[t]{3}{*}{ LAM } & $50 \%$ & 7.5 & 7.62 & 22056 & 100.58 & 100.12 \\
\hline & $100 \%$ & 15 & 14.85 & 43140 & 99.18 & \\
\hline & $150 \%$ & 22.5 & 22.52 & 66628 & 100.60 & \\
\hline \multirow[t]{3}{*}{ RAL } & $50 \%$ & 15 & 14.83 & 106479 & 98.94 & 99.89 \\
\hline & $100 \%$ & 30 & 29.88 & 214516 & 99.67 & \\
\hline & $150 \%$ & 45 & 45.47 & 326302 & 101.07 & \\
\hline
\end{tabular}

$\mathrm{n}=3$;LAM: lamivudine; RAL: raltegravir

\section{Robustness}

Standard solution $45 \mu \mathrm{g} / \mathrm{ml}$ and $90 \mu \mathrm{g} / \mathrm{ml}$ of LAM and RAL was prepared and analysed using the varied flow rate and mobile phase composition along with the actual mobile phase composition in the method. System suitability parameters were compared with that of method precision. The retention time, plate count, tailing factor obtained for a change of flow rate, variation in mobile phase was found to be within the acceptance criteria. Hence the method is robust. The result of the robustness study of the developement assay method was established in table 8.

Table 8: Robustness for LAM and RAL

\begin{tabular}{llllll}
\hline \multirow{2}{*}{ Drug } & Flow rate & \multicolumn{2}{l}{ System suitability USP } & Change in & \multicolumn{2}{l}{ System suitability USP } \\
\cline { 3 - 4 } & (ml/min) & Plate & Tailing & Pobile phase & Tailing \\
\hline LAM & 0.8 & 2736.08 & 1.53 & actual & 1.54 \\
& 0.9 & 2559.08 & 1.65 & $10 \%$ more & 1.65 \\
RAL & 1.0 & 2540.88 & 1.53 & $10 \%$ less & 2559.08 \\
& 0.8 & 3910.92 & 1.31 & actual & 2865.60 \\
& 0.9 & 3511.35 & 1.35 & $10 \%$ more & 3884.75 \\
& 1.0 & 3456.84 & 1.29 & & 1.29 \\
\end{tabular}

$\mathrm{n}=3$;LAM: lamivudine; RAL: raltegravir

Table 9: Degradation studies results for LAM and RAL

\begin{tabular}{|c|c|c|c|c|}
\hline \multirow[t]{2}{*}{ Condition } & \multicolumn{2}{|l|}{ LAM } & \multicolumn{2}{|l|}{ RAL } \\
\hline & Area & \% Degraded & Area & \% Degraded \\
\hline Control & 45921 & - & 213936 & - \\
\hline Acid & 45623.56 & 5.25 & 213754.25 & 5.04 \\
\hline Alkali & 45589.54 & 5.06 & 213624.87 & 5.17 \\
\hline Peroxide & 45423.69 & 5.87 & 213542.24 & 6.25 \\
\hline Thermal & 45752.84 & 3.23 & 213564.36 & 2.54 \\
\hline Photo & 45856.56 & 1.15 & 213896.21 & 1.13 \\
\hline
\end{tabular}

LAM: lamivudine; RAL: raltegravir

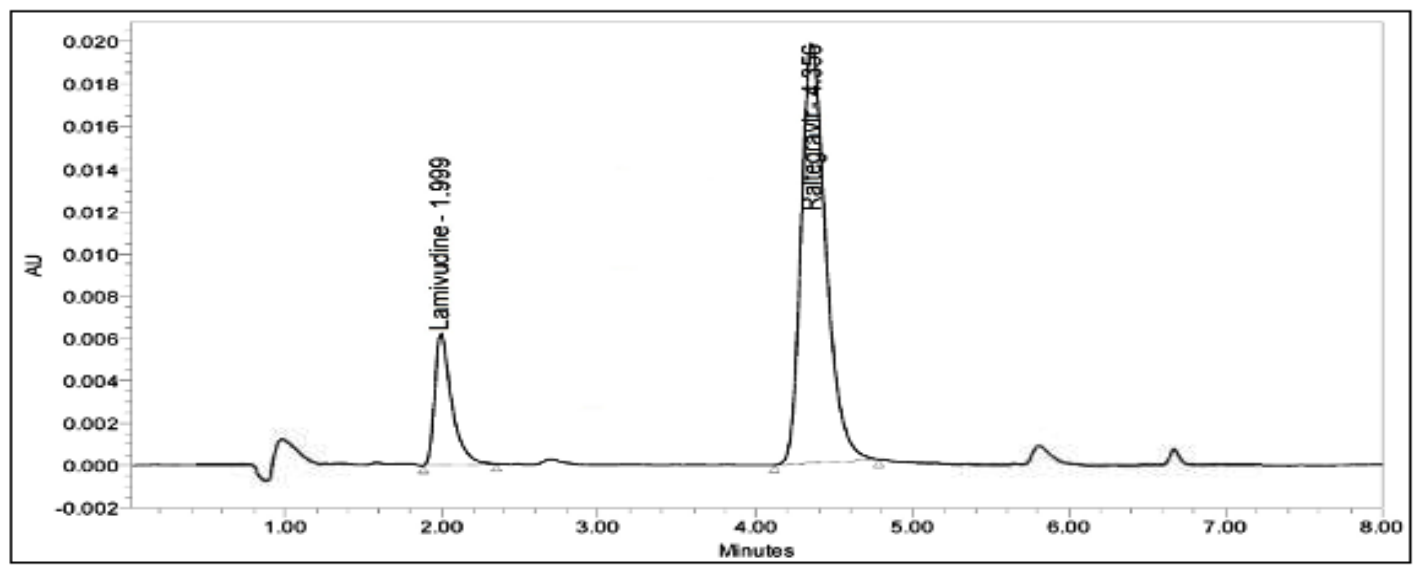

Fig. 6: Acid degradation of LAM and RAL 


\section{Forced degradation studies}

The stability studies were determined by applying the physical stress to the product. Results in forced degradation were shown in table 9 and blank was recorded. The results of forced degradation studies for the simultaneous estimation of LAM and RAL were in limits, and respective chromatograms were represented. It was observed that the drug degrades as shown by the decreased areas in the peaks when compared to peak areas of the same concentration of the non-degraded drug, with additional degradation peaks. Percent degradation was calculated by comparing the areas of the degraded peaks at each degradation condition with the corresponding areas of the peaks of both the drugs under non-degradation condition. Degradation studied were performed and it was observed that no interference of degradants as shown in fig. 6-10.

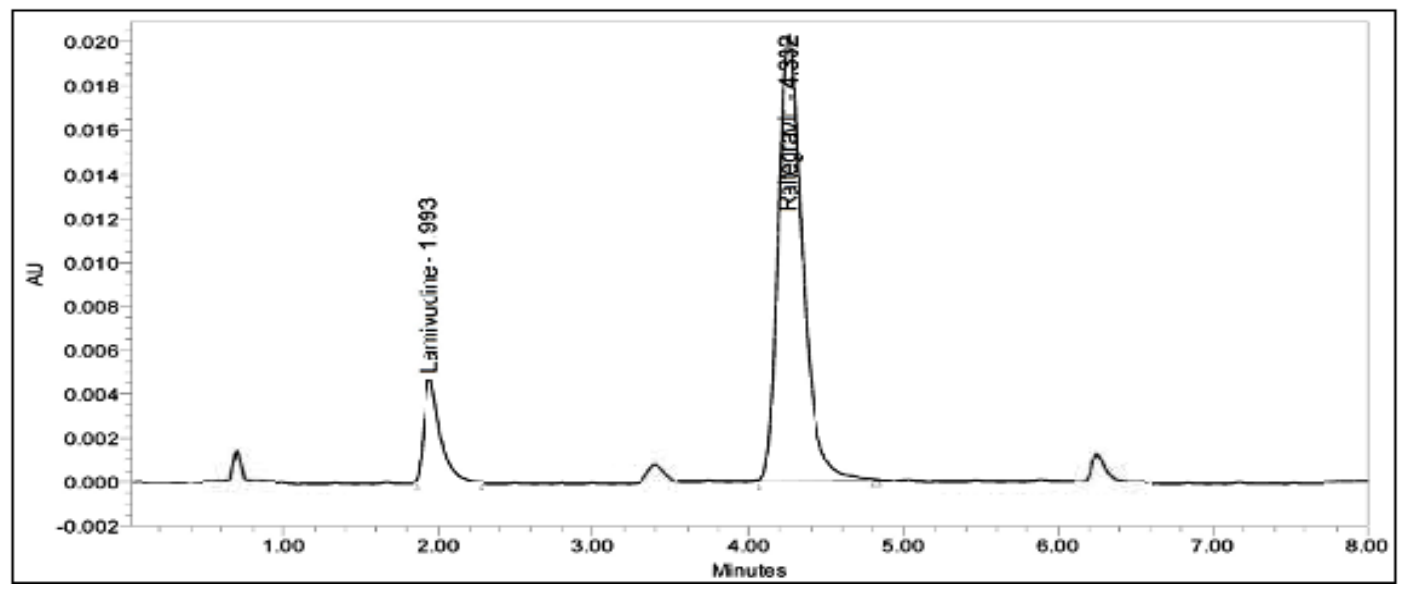

Fig. 7: Alkali degradation of LAM and RAL

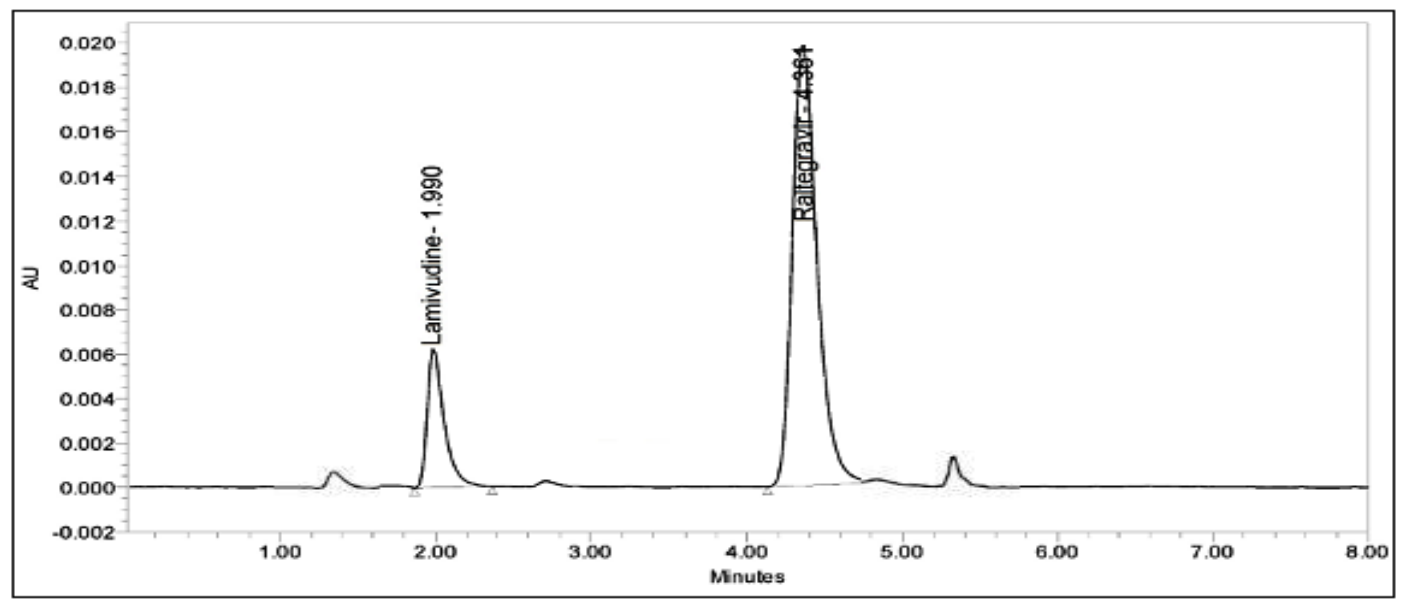

Fig. 8: Thermal degradation of LAM and RAL

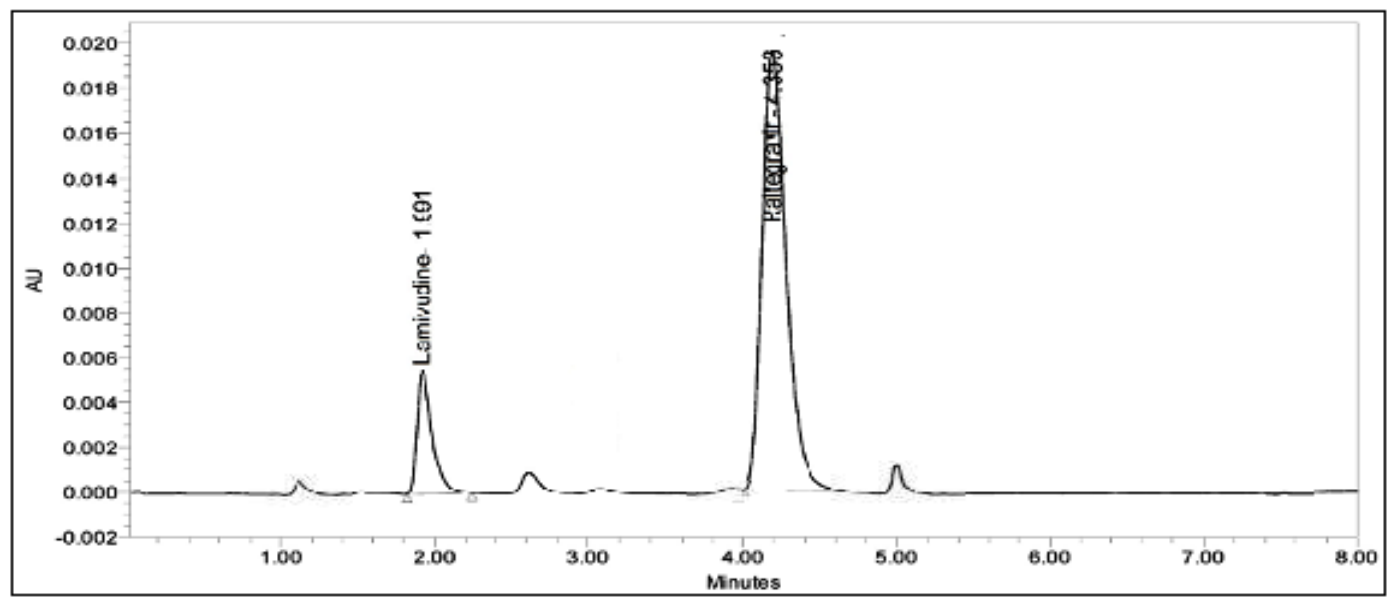

Fig. 9: Photolytic degradation of LAM and RAL 


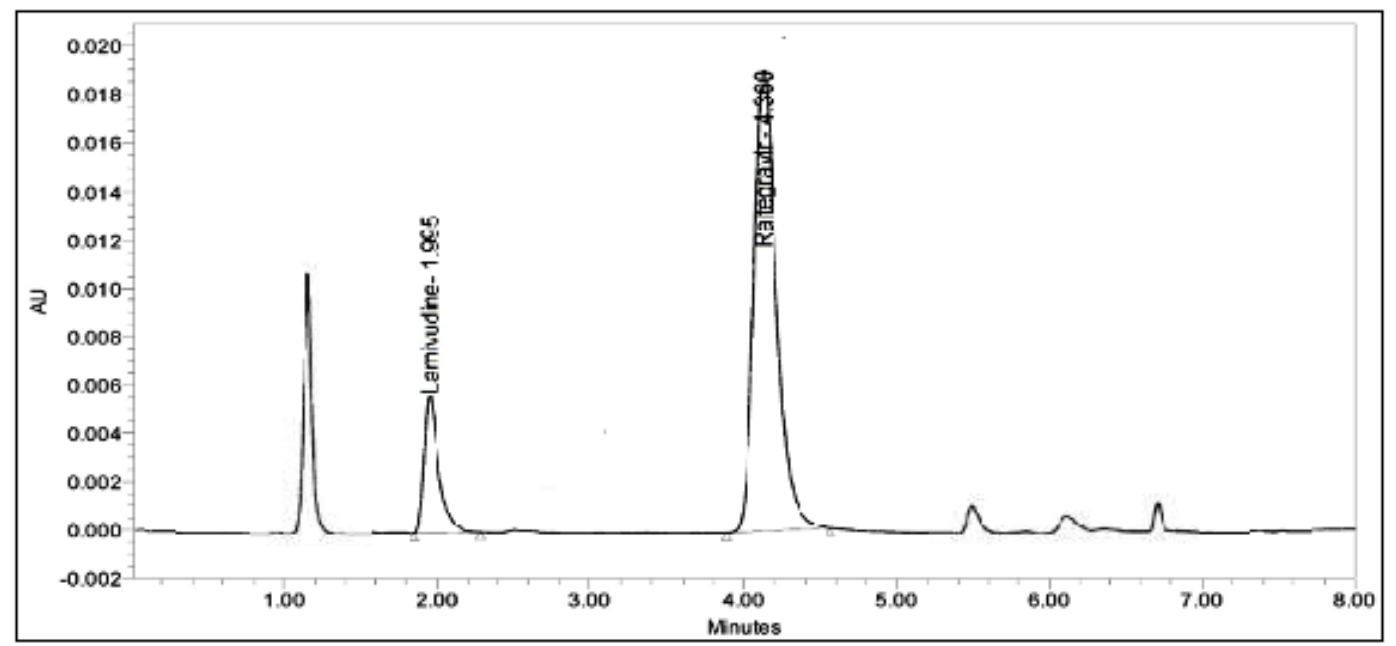

Fig. 10: Oxidative degradation of LAM and RAL

\section{CONCLUSION}

A simple and selective RP-HPLC method was described for the determination of LAM and RAL dosage forms. The retention time of LAM and RAL was $1.99 \mathrm{~min}$ and $4.34 \mathrm{~min}$ respectively. The linearity of LAM and RAL was found to be linear with a correlation coefficient of 0.998 and 0.999 . The acceptance criteria of precision were RSD should be not more than $2.0 \%$ and the method shows precision 1.31 and 0.96 for LAM and RAL which shows that the method was precise. The results of forced degradation studies for the simultaneous estimation of LAM and RAL were in limits, and respective chromatograms were represented. Hence the method was successfully applied for degradation studies, and HPLC method for simultaneous estimation of LAM and RAL was novel, simple, precise, accurate, robust and cost-effective method.

\section{AUTHORS CONTRIBUTION}

All the authors have contributed equally

\section{CONFLICTS OF INTERESTS}

Declare none

\section{REFERENCES}

1. K. Ananda Kumar. Method development and validation of uvspectroscopic method for the estimation of lamivudine as an active pharmaceutical ingredient and in tablet dosage form. Int J Pharm Health Care Res 2017;5:129-37.

2. Krishna Reddy NV, Phani RS, Ramesh R. New RP-HPLC method development for analysis and assay of lamivudine in the formulation. Int J Res Pharm Biomed Sci 2011;2:220-3.

3. Kalpesh V, Prabodh Sapkale. Development and validation of uv spectroscopic method for estimation of lamivudine in tablet dosage form. Int J Curr Pharm Res 2017;9:86-9.

4. Mandloi DK, Tyagi PK. Method development and validation of rp-hplc in the application of In-vitro dissolution study of lamivudine in bulk drug and tablet formulation. J Chem Pharm Res 2009;1:286-96.

5. Lakshmana Rao. Validated RP-HPLC method for determination of raltegravir in pharmaceutical preparations. Int J Res Pharm Chem 2012;2:258-64.
6. Rambabu Kuchi. New RP-HPLC method development and validation for analysis of antiviral drug raltegravir. Int J Res Pharm Bio Sci 2011;2:196-202.

7. Mary C. Long a sensitive HPLC-MS method for the determination of raltegravir in human plasma. J Chrom B 2008;867:165-71.

8. Sudha T, Raghupathi T. RP-HPLC and ultraviolet spectrophotometric method for the estimation of raltegravir potassium in bulk and in tablet dosage form. Global J Med Res 2011;11:8-16.

9. Rambabu K, Balamurali K, Sambasiva R. New rp-hplc method development and validation for analysis of antiviral drug raltegravir. Int J Res Pharm Biomed Sci 2011;2:132-5.

10. Saritha Chukka, Shayeda Shaik. Development and characterization of gastroretentive drug delivery system for ritonavir tablets using natural polymers. Asian J Pharm Clin Res 2017;10:318-22.

11. G Raveendra Babu, A Lakshmana Rao, J Venkateswara Rao. A rapid RP-HPLC method development and validation for the quantitative estimation ribavirin in tablets. Int J Pharm Pharm Sci 2015;7:60-3.

12. Hemanth Kumar AK, Sudha V, Leelavathi A, Geetha Ramachandran. A rapid isocratic HPLC method for the quantification of ritonavir in human plasma. Int J Pharm Pharm Sci 2016;8:64-8.

13. Rami R, Reddy BS, Raman NV, Jyothi G. Validated stabilityindicating UPLC assay method and degradation behavior of raltegravir potassium. Int J Pharm Tech 2012;4:4045-59.

14. Veena D Singh, Sanjay J Daharwal. Optimization of an RP-HPLC method for simultaneous estimation of lamivudine and raltegravir in the binary mixture by using design of the experiment. Eurasian J Anal Chem 2012;12:179-95.

15. Honeesha Nandimandalam, D Gowri Sankar. Simultaneous RPHPLC method development and validation for lamivudine and raltegravir in bulk dosage forms. Am J Pharm Tech Res 2015;5:249-56.

16. International conference on harmonization: ICH: Q2(R1), validation of analytical procedures: text and methodology; 1995.

17. International conference on harmonization ICH: Q2B, analytical validation-methodology; 1996. p. 24.

18. International conference on harmonization ICH: Q2A, text on validation of analytical procedure; 1994. p. 22. 